Reeds sinds geruimen tijd gingen er voortdurend stemmen op, die wezen op de onbevredigende ontwikkeling van het N.V.-wezen in Nederland. Reeds in 1937 wees Schadee in een artikel in de N.V. er op, dat men den N.V.-vorm in de kleine ondernemingen niet als den meest gewenschten vorm moest beschouwen en dat de praktijk, getuige het groote aantal oprichtingen voor kleinere zaken, daarmede op den verkeerden weg was. De statistieken wezen uit, dat een groot aantal N.V.'s werden opgericht voor doeleinden, waarvoor de N.V.-vorm oorspronkelijk niet was bedoeld.

Daarbij kwam nog een factor en wel van fiscale zijde. De organisatie van ons belastingwezen was zoodanig, dat de omzetting van bestaande zaken en de oprichting van nieuwe zaken in den rechtsvorm van een naamlooze vennootschap belangrijke voordeelen met zich mede brachten. Het gevolg was dan ook, dat tot de keuze van den N.V.-vorm werd overgegaan, uitsluitend op grond van deze voordeelen, waarbij van fiscale zijde ernstig bezwaar werd gemaakt, bezwaren die inderdaad terecht konden worden genoemd. Tallooze maatregelen werden overwogen en ook genomen, teneinde de schadelijke gevolgen van dit streven zooveel mogelijk te beperken. De overgang van de uitkeeringsbelastingen naar de winstbelasting was al een belangriike stap, maar de ontwikkeling van onze belastingwetgeving van het laatste jaar was oorzaak, dat het in een groot aantal gevallen in fiscaal opzicht zeer nadeelig werd om een zaak in N.V.-vorm te drijven. Een sterk verhoogd tarief van de winstbelasting en de mededeeling, dat het tarief over 1941 nog zeer belangrijk zal worden verhoogd, de in het vooruitzicht gestelde vermogensbelasting voor naamlooze vennootschappen en de eveneens in het vooruitzicht gestelde wijzigingen ten aanzien van de waardeeringsbepalingen van de Winstbelasting maakten den N.V.-vorm in vele gevallen zeer onereus.

Voor talrijke ondernemingen zou de eenige oplossing zijn het besluit tot liquidatie van de naamlooze vennootschap en het bedrijf voort te zetten onder een anderen vennootschapsvorm. Toch zou men hiertoe in de meeste gevallen niet zijn overgegaan wegens de groote moeilijkheden, aan een liquidatie verbonden. Die moeilijkheden waren tweeledig: 1. de fiscale bezwaren.

2. de juridische bezwaren, verbonden aan de oprichting van een andere vennootschap.

Allereerst de fiscale bezwaren, die vooral groot waren in verband met de invoering van de Inkomstenbelasting 1941.

a. Van het geheele liquidatiesaldo, dus ook van de overgangsreserve zou winstbelasting worden geheven op den voet van het tarief, dat over 1941 nog moest worden vastgesteld.

b. De aandeelhouders zouden, tengevolge van de Inkomstenbelasting 1941, inkomstenbelasting moeten betalen over het aan hun uitgekeerde liquidatiesaldo.

c. Waardevermeerderingsbelasting en registratierechten zouden moeten worden betaald bij overgang van onroerende goederen.

d. Omzetbelasting zou moeten worden betald voor leveringen en diensten door de naamlooze vennootschap ter zake van haar vereffening jegens de aandeelhouders.

m a b blz. 358 
e. Super-dividendbelasting zou moeten worden betaald krachtens het .,besluit op de dividendbeperking 1941".

Het is wel duidelijk, dat deze bezwaren in de meeste gevallen voor de betrokken aandeelhouders onoverkomeliik zouden geweest zijn.

Het is nu het Liquidatiebesluit 1941, dat deze bezwaren tracht te ondervangen door onder bepaalde voorwaarden verschillende vrijstellingen aan de betrokken vennootschap of aandeelhouders te verleenen.

Wat nu de juridische bezwaren betreft, deze worden door het liquidatiebesluit niet ondervangen. Toch zijn ook deze bezwaren in vele gevallen groot en wel voornamelijk wegens het volgende. Het moge waar zijn, dat bij de oprichting van vele naamlooze vennootschappen. de fiscale voordeelen een belangriike rol hebben gespeeld, evenzeer is het echter waar, dat sinds de oprichting. de interne verhoudingen in vele naamlooze vennootschappen belangrijk zijn veranderd. In het eene geval is het aantal aandeelhouders belangriik uitgebreid, zoodat de vereischte overeenstemming om tot een nieuwen vennootschapsvorm te komen, niet of zeer moeilijk kan worden verkregen, in andere gevallen zal de wensch tot uittreden van enkele vennooten door de liquidatie dusdanig worden versterkt, dat het voortbestaan van de zaak zelve zal worden bedreigd. De onderhandelingen over nieuwe vennootschapscontracten zullen de bron worden van zoovele moeilijkheden, dat men de financiëele nadeelen van den N.V.-vorm prefereert boven de voordeelen bij liquidatie. Daarbij komen dan nog de moeilijkheden, bij overlijden van een of meer vennooten, vooral met het oog op het voortbestaan van de onderneming.

Dat deze bezwaren in het algemeen wel worden gevoeld, blijkt uit de aankondiging in de couranten, waarbii een regeling van de commanditaire vennootschappen in het vooruitzicht wordt gesteld. Misschien dat hierbij enkele moeilijkheden. waarmede in het bijzonder de familievennootschappen hebben te kampen. worden opgelost.

Het liquidatiebesluit geeft dus een aantal bepalingen, waarbij fiscale teqemoetkominqen worden verleend, wanneer de liquidatie onder bepaalde voorwaarden plaats vindt. De regeling valt eigenlijk uiteen in twee gedeelten, al naar de wijze waarop de liquidatie geschiedt.

Het eerste geval onderstelt het als het normale geval, n.l. een ontbinding van de vennootschap en vereffening in dier voege, dat zij alle belangen en bezittingen, alsmede alle verplichtingen, voorzoover nog niet voldaan, overdraagt of heeft overgedragen aan een firma.

Het tweede geval (zie art. 6) veronderstelt den overgang van het geheele vermogen op de gezamenlijke of afzonderlijke aandeelhouders. Hierop komen wij straks nader terug.

Wanneer wij deze beide gevallen bezien, valt onmiddellijk het eigenaardige karakter van deze liquidatie op. Onze wet op de naamlooze vennootschappen kent bij liquidatie eigenlijk maar één methode en wel die van de vereffening. Zooals van der Heyden ook zegt (pag. 474) „Na ontbinding treedt noodzakelijk vereffening in. Het besluit tot ontbinding omvat stilzwijgend dat tot vereffening en omgekeerd" en verder ..De rechten moeten worden gerealiseerd, de verplichtingen worden voldaan, hetgeen overblijft moet onder rechthebbenden worden verdeeld". Dit is dus een andere liquidatie, dan in de regeling wordt voorgesteld. Het besluit stelt zich voor, dat alle bezittingen en schulden overgaan op de rechthebbenden als uitkeering bij liquidatie. In de praktijk behoeft men zich echter bij algemeene medewerking van de betrok- 
ken partijen van deze moeilijkheden niet veel aan te trekken. Wanneer enkele schuldeischers om bepaalde redenen echter niet willen medewerken, komt men bij de liquidatie voor groote moeilijkheden te staan. De Leidraad zegt, dat men in een dergelijk geval den weg van de vereffening moet volgen. Dit kan echter veel moeilijkheden en kosten met zich medebrengen.

Vervolgens moet men in het oog houden, dat deze uitkeeringen geschieden in verhouding tot het aandeelenbezit van de vennooten op het overdrachtstijdstip (art. 5 le lid onder 1). Alleen wanneer men aan deze voorwaarden voldoet heeft men recht op de belastingvrijstellingen. Wanneer dus bepaalde aandeelhouders niet voor vennoot in aanmerking komen, zijn de overige aandeelhouders verplicht, de aandeelen voor dat het ontbindingsbesluit genomen wordt, te koopen. Het overdrachtstijdstip kan in dit geval dus niet liggen vóór het moment van den aandeelenverkoop. Dit kan ook weer bezwaarlijk zijn, zoodat men dan genoodzaakt wordt een dergelijken aandeelhouder wel als vennoot op te nemen om hem dan op een later tijdstip uit de firma te laten treden.

Behandelen wij nu het eerste geval:

Een eerste punt is, dat de regeling eischt, dat men bezittingen en verplichtingen overdraagt aan een "firma".

Hiermede wordt niet alleen bedoeld de firma in juridischen zin, maar de regeling breidt dit begrip uit en omvat daarmede ook de commanditaire vennootschap, waarvan de vennooten natuurlijke personen zijn, die op het overdrachtstijdstip aandeelhouder zijn van de naamlooze vennootschap. De persoon, die eenig aandeelhouder is op dit moment, valt eveneens onder dit begrip. De eerste uitvoeringsbeschikking geeft een nog verdere uitbreiding van dit begrip. In overeenstemming met artikel 17 van de Inkomstenbelasting 1941 omvat het besluit ook onder dit begrip de commanditaire vennootschap, waarbij de commanditaire vennoot niets meer is dan geldschieter en dus in geen enkel opzicht medegerechtigd tot het bedrijfsvermogen.

Ook de vraag, of de maatschap onder het begrip ,firma" van het Liquidatiebesluit zou kunnen worden gebracht, is beantwoord in art. 9 , 3e. lid van de Eerste Uitvoeringsbeschikking, waarin nadrukkelijk is vastgelegd, dat de Secretaris-Generaal zulks kan bepalen.

Tenslotte wordt nog toegestaan bij een commanditaire vennootschap, waarin de commanditaire vennoot uitsluitend geldschieter is, dat ook de naamlooze vennootschap deze functie kan vervullen. Dit is dus in afwijking van de algemeene strekking van het besluit, om zooveel mo gelijk naamlooze vennootschappen te doen verdwijnen (zie in dit verband art. 1, 2e. lid, waarbij de overdracht alleen kan geschieden aan natuurlijke personen en ook artikel 7, waarbij de achterwege gebleven belastingen alsnog kunnen worden geheven, wanneer binnen twee jaren een vennoot toetreedt, die geen natururlijk persoon is). Vandaar, dat dan ook de eisch wordt gesteld, dat de naamlooze vennootschap stille vennoot is en blijft, of het bankbedrijf uitoefent. Dus de verhouding mag niet anders zijn dan die van financier. (Men voldoet dan ook niet meer aan deze voorwaarde, wanneer de beheerende vennoot aandeelen in deze venootschap verwerft, anders dan dcor huwelijk en vererving). Voldoet men echter aan de hierboven gestelde voorwaarden, dan valt ook deze vorm nog onder het begrip .,firma". Is een naamlooze vennootschap eenig aandeelhouder, dan valt ook zij onder het begrip .firma".

m a b blz, 360 
Onder het begrip ,overdragen" kan ook worden verstaan de uitkeering van de overgebleven bezittingen aan de gezamenlijke aandeelhouders. De firma behoeft er dus nog niet te zijn, mits de verkrijging van de bezittingen is geschied voor bedrijfsdoeleinden (art. 1, 3e lid). De hoofdgedachte van het besluit wordt hier dus gehandhaafd (zie ook in dit verband art. 5, 1e lid onder D, waar gesproken wordt van het latere tot stand komen van de firma).

Het perscommuniqué beweert, dat deze bepaling betrekking heeft op het geval, dat het bedrijf van de N.V. niet voortgezet wordt als afzonderlijk bedriif, doch met het reeds bestaande bedrijf van de aandeelhouders wordt versmolten en dan noemt het communiqué als voorbeeld, dat een reeds bestaande firma houdster is van alle aandeelen in de N.V., die het kantoorgebouw van de firma in eigendom heeft. Dus een zeer speciaal geval.

Wanneer en hoe moet men nu die bezittingen en verplichtingen van de N.V. overgedragen. Art. 1, le lid onder 2 zegt, dat men een overdrachtstijdstip moet kiezen en dat dit moet liggen, tusschen 31 December 1940 en den dag, waarop sedert het in werking treden van het besluit, 2 maanden zijn verloopen. Deze laatste tijdsbepaling is inmiddels bij de Eerste Uitvoeringsbeschikking veranderd in den dag ,waarop sedert de afkondiging van de beschikking 3 maanden zijn verloopen". Welke keuze men hier moet doen, hangt af van het speciale geval. De keuze kan echter van veel invloed zijn op het bedrag aan belastingen, dat men eventueel zal moeten betalen.

De overdracht zelve, geschiedt door middel van een overdrachtsbalans, die men moet opmaken, met in achtneming van de artikelen 10 en 11 van het Besluit op de Inkomstenbelasting 1941. Het perscommuniqué zegt hiervan, dat men er van kan uitgaan, dat het bedrijf door denzelfden ondernemer wordt voortgezet. Ongerealiseerde winsten behoeven dan ook niet tot uitdrukking te worden gebracht. De bedoeling is dus wel, dat de geheime reserves op de overdrachtsbalans tot uiting zullen worden gebracht, een verplichting die in heel wat gevallen de lust tot liquidatie wel zal doen verminderen. Eventueele goodwill zal echter niet op deze balansen moeten worden opgevoerd.

Ook de afschrijvingen worden vastgesteld met in achtneming van hetgeen in art. 10 en 11 van de Inkomstenbelasting 1941 is bepaald. De firma kan hetzelfde systeem kiezen, als de vereffenaars hebben gedaan bij de vaststelling van de overdrachtsbalans. $Z_{i j}$ kan echter ook de continuiteit met de N.V. verbreken en zelfstandig met de afschrijving van het actief beginnen, daarbij voor het uitgangspunt de keuze hebbende, tusschen aanschaffingsprijs en bedrijfswaarde, indien deze laatste lager is. Als principe geldt echter in alle gevallen, dat men moet blijven binnen de grenzen, die door artikel 10 en 11 van de Inkomstenbelasting 1941 zijn gesteld.

Het saldo van deze balans is dus de uitkeering bij liquidatie (zie artikel 2) en tevens de basis voor de berekening van de te betalen winstbelasting over de periode, die eindigt met het overdrachtstijdstip. Ook over het bedrag van de overgangsreserve wordt de winstbelasting betaald, op de wijze zooals in artikel 41 van het Besluit op de Winstbelasting is bepaald. We zien dus hieruit, dat de functie van de overdrachtsbalans zeer belangrijk is, niet alleen omdat ze de periode, waarover winstbelasting moet worden betaald, afsluit, maar ook omdat ze weer de basis is voor het bepalen van de winst in de firma (art. 3. lid 2). 
De geheele winst, welke gemaakt is, na het overdrachtstijdstip, geldt als te zijn gemaakt in de firma en is als zoodanig onderworpen aan de Inkomstenbelasting.

Het spreekt wel vanzelf, dat het nog te betalen bedrag aan winstbelasting in de openingsbalans voor de firma als passief bij de berekening van het zuiver vermogen in mindering wordt gebracht (art. 3, lid 2), in tegenstelling tot de winstbepaling bij de overdrachtsbalans, waarin de te bepalen winstbelasting over de periode eindigende met het overdrachtstijdstip niet in mindering wordt gebracht.

Verder geeft het besluit nog enkele bepalingen omtrent de termijnen, die in acht moeten worden genomen. De Eerste Uitvoeringsbeschikking geeft dienaangaande nog enkele wijzigingen.

Het besluit tot ontbinding moet plaats vinden na 31 December 1940 of vóór 16 December 1941 (d.w.z. 2 maanden na het in werking treden van de Eerste Uitvoeringsbeschikking). Het ontbindingsbesluit moet door de algemeene vergadering van aandeelhouders worden genomen in overeenstemming met de daarop betrekking hebbende bepalingen van de statuten.

De vereffenaars moeten binnen twee weken na het ontbindingsbesluit bij den inspecteur, de verklaring omschreven in artikel 5, lid 2, indienen, waarin o.a. de datum van het ontbindingsbesluit en het overdrachtstijdstip moeten worden vermeld. Mocht het besluit tot ontbinding reeds eerder zijn genomen, dan geldt de termijn van twee weken vanaf het moment van inwerking treden van de eerste Uitvoeringsbeschikking, dus vanaf 16 October 1941.

De overdrachtsbalans moet worden ingeleverd binnen 3 maanden na het inwerking treden van de eerste Uitvoeringsbeschikking, dus vóór 16 Januari 1942, wanneer het overdrachtstijdstip valt voór het in werking treden van het besluit. In het andere geval geldt de termijn van 3 maanden na het overdrachtstijdstip. Eigenaardig is, dat de Uitvoeringsbeschikking dezen termijn niet heeft doen deelen in de verlenging. Aangifte voor de winstbelasting moet binnen denzelfden termijn geschieden. In bijzondere gevallen kunnen de termijnen door den Inspecteur worden verlengd.

Welke zijn nu de voordeelen, die men met een liquidatie van de ven. nootschap overeenkomstig de hierboven genoemde regelen verkrijgt:

Artikel 3 zegt hieromtrent, dat voor de heffing van de inkomstenbelasting, dividendbelasting en commissarissenbelasting, de N.V. geacht wordt te zijn ontbonden en vereffend, onmiddellijk vooor het overdrachtstijdstip en in elk opzicht te zijn opgevolgd door de firma. Dit beteekent dus, dat de winst, die gemaakt is, vóór het overdrachtstijdstip, getroffen wordt door de winstbelasting. Als concessie geldt daarbij, dat deze winstbelasting geheven wordt naar de tegenwoordige tarieven i.c. dus $261 / 2$ en $311 / 2 \%$. In verband met de in uitzicht gestelde verhoogde tarieven voor de winstbelasting 1941 , is dit dus een tegemoetkoming. Bovendien wordt de overgangsreserve tegen hetzelfde tarief belast (zie art. 2, lid 2).

Een belangrijk voordeel is verder, dat de liquidatie-uitkeeringen zijn vrijgesteld van de inkomstenbelasting en van de dividendbelasting (artikel 3). Vooral voor de naamlooze vennootschappen met groote reserves is dit dus een voordeel van groote beteekenis, nu de inkomstenbelasting 1941 al deze liquidatie-uitkeeringen, voor zoover deze meer bedragen dan het gestorte kapitaal, belast (art. 31, 1e. lid onder 2). 
De geheele winst van 1941, voor zoover deze vóor het overdrachtstijdstip is gemaakt, valt dus buiten de inkomstenbelasting. Tantièmes, na het overdrachtstijdstip genoten door de firmanten, zijn eveneens vrij van Joonbelasting en inkomstenbelasting. Dat ongerealiseerde winsten belastingvrij overgaan, is reeds hiervoor behandeld. Eventueel, na het overdrachtstiidstip geheven commissarissenbelasting wordt gerestitueerd.

Het hangt dus nu af van de tariefklasse, waarin de aandeelhouders voor de inkomstenbelasting vallen, of men het overdrachtstijdstip naar een vroegeren datum zal verschuiven. Is de tariefklasse in het algemeen hooger dan de $311 / 2 \%$, die men als winstbelasting betaalt, dan zal men het overdrachtstijdstip zoo laat mogelijk stellen.

Verder zijn de leveringen en diensten door de naamlooze vennootschap ter zake van haar vereffening verricht aan of jegens de firma, vrijgesteld van omzetbelasting, voor zoover zij vóór 1 Maart 1942 plaats vinden (art. 4 lid 1).

Tenslotte geldt een vrijstelling van evenredig registratierecht en van waardevermeerderingsbelasting, wanneer onroerende zaken vóór 1 Maart 1942 door de firma worden verkregen. Den termijn tot 1 Maart 1942 kan de inspecteur verlengen.

Het besluit voegt er nog aan toe, dat voor de heffing van registratierecht en waardevermeerderingsbelasting de verkrijging van onroerende zaken door de naamlooze vennootschap aangemerkt wordt als verkrijging door de firma. Als basis voor de berekening van de waardevermeerderingsbelasting geldt dus de datum en de aanschaffingsprijs van de naamlooze vennootschap.

Wij vestigen er de aandacht op, dat hier steeds gesproken wordt van overgang aan de firma, waarmede dus bedoeld wordt het begrip "firma”, zooals het liquidatiebesluit, alsmede de eerste Uitvoeringsbeschikking dat omschrijft. Bij de behandeling van artikel 6 komen wij hierop terug.

Superdividendbelasting wordt evenmin geheven, hetgeen natuurlijk van heel veel belang is, omdat in verband met de overgangsreserves de uitkeering het percentage van $6 \%$ wel in de meeste gevallen zal overschrijden.

Hetgeen hierboven is behandeld geldt dus voor het geval, dat de bezittingen en schulden van de vennootschap overgaan aan de firma van aandeelhouders in evenredigheid van hun aandeelen, dus het normale geval.

Behandelen wij nu het afwijkende geval, zooals het vastgelegd is in artikel 6, waarin met overdracht op een firma wordt gelijkgesteld elke andere bij de vereffening plaats vindende overgang van het vermogen van een naamlooze vennootschap op haar gezamenlijke of afzonderlijke aandeelhouders. De toelichting geeft aan, dat hiermede wordt bedoeld de overgang van het vermogen aan aandeelhouders, zonder dat deze het bedriif van de N.V. kunnen voortzetten, omdat het kan voorkomen, dat datgene, wat bedrijf is voor een N.V., geen bedrijf meer is voor de gezamenlijke aandeelhouders, b.v. de exploitatie van een woonhuis of van een effectenportefeuille. Hier is dus sprake van gewoon vermogensbeheer. Artikel 6 behandelt dus eigenlijk het geval van liquidatie van het bedrijf, terwijl artikel 1 het normale geval, n.l. dat van voortzetting van het bedrijf omvat. In tegenstelling met artikel 1, lid 3 wordt hier dan ook niet gesproken over overdracht voor bedrijfsdoeleinden. De wijze van winstbepaling van de firma is op dit geval uiter- 
aard niet van toepassing. De toelichting en de eerste Uitvoeringsbeschikking bepalen, dat de waardeering van de activa op de overdrachtsbalans dient te geschieden volgens de verkoopwaarde. Ongerealiseerde winsten worden hier dus getroffen door de winstbelasting, hetgeen ook logisch is, omdat het bedrijf eindigt. Dezelfde waardeering is van toepassing op het geval waarin de bezittingen der naamlooze vennootschap worden verkocht aan derden of aan enkele aandeelhouders en het geld onder de gezamenlijke aandeelhouders wordt verdeeld. Over het algemeen is deze wijze van handelen dus fiscaal zeer onvoordeelig, zoodat men beter het bedrijf voorloopig kan overdragen aan de firma van aandeelhouders.

De algemeene regel voor de gevallen van artikel 6 is dus, dat de activa op de overdrachtsbalans gewaardeerd worden volgens verkoopwaarde, tenzij en voor zoover een gezamenlijke vervreemding van activa voor de hand ligt, in welk geval de betreffende activa gewaardeerd worden op bedrijfswaarde, opgevat in den zin van artikel 10, lid 2 , Inkomstenbelasting 1941 .

Dit beteekent dus, dat in de activa een zeker bedrag voor goodwill kan worden gecalculeerd, want het complex van activa kan een hoogere waarde hebben dan de afzonderlijke deelen van dat complex. Voor het geval, dat deze activa worden uitgekeerd of overgedragen aan de gezamenlijke aandeelhouders, worden aan de waardeering bepaalde maxima gesteld. Ook deze bepaling past weer in het raam van het geheel, want in zekeren zin is dit geval weer een voortzetting van het bedrijf van de N.V. Dit alles echter onder de voorwaarde, dat deze activa bestemd waren on door de N.V. te worden gebruikt of verhuurd. Het eene maximum is dan de bedrijfswaarde op 9 Mei 1940, verminderd met de noodige afschrijvingen wegens slijtage. Het andere maximum is de boekwaarde volgens het systeem van waardeering volgens de winstbelasting (Eerste Uitvoeringsbeschikking Artikel 2, lid 2). Dit laatste geval is dus een belangrijke uitzondering. Volgens de Leidraad berust deze uitzondering op de gedachte, dat wanneer de gezamenlijke aandeelhouders deze goederen verkrijgen, dit wel blijvend zal zijn, zoodat het wel onbillijk zou zijn om ongerealiseerde winst te belasten. Het is immers heel wel mogelijk, dat deze winst na verloop van tijd, tengevolge van algemeene prijsdaling, weer automatisch verdwijnt.

Gewoonlijk zal de boekwaarde, verminderd met de afschrijvingen, volgens het systeem, dat de vennootschap ten opzichte van de winstlasting heeft toegepast, wel de laagste zijn. Verder merken wij nog op. dat hier gesproken wordt van activa, die bestemd zijn door de N.V. te worden gebruikt of verhuurd. Handelsvoorraden vallen hier dus buiten.

Worden deze activa dus niet overgedragen aan de gezamenlijke aandeelhouders, onder voorwaarde van participatie in verhouding tot hun belang in de N.V., maar b.v. aan enkele aandeelhouders, dan gelden als maatstaven van waardeering de verkoopwaarde en de bedrijfswaarde, dus waardeeringen die in het algemeen belangrijk boven de boekwaarde van deze activa gelegen zijn. Voor de belastingheffing geeft dit dus belangrijke consequenties.

Evenals bij den overgang aan de firma van aandeelhouders, wordt ook bij den overgang aan de gezamenlijke aandeelhouders op grond van artikel 6 verondersteld, dat alles wat de overdrachtsbalans aangeeft, op den overdrachtsdatum overgaat op de maatschap van gezamenlijke aandeelhouders (Eerste Uitvoeringsbeschikking art. 3, lid 1). Het is dus 
duidelijk, dat wanneer de fictieve maatschap winst maakt door verkoop van een gebouw, de winst voor de leden van deze niet meer in bedrijf zijnde maatschap, geen inkomen is.

Uitkeeringen op aandeelen, gedaan na het ontbindingsbesluit zijn evenmin inkomen voor de leden van de maatschap (zie art. 10 Eerste Uitvoeringsbeschikking).

Tantièmes worden op grond van artikel 6 anders behandeld, dan in het normale geval van liquidatie. Normaal zijn tantièmes enz., na het overdrachtstijdstip genoten, geen inkomen voor de firmanten. $\mathrm{Z}_{\mathrm{ij}}$ zijn immers in de voorgaande periode verdiend en hebben niets met de bedrijfswinst van de firma te maken. In het geval van artikel 6 moet de zaak anders worden gesteld, want het bedrijf van de gezamenliike aandeelhouders is geëindigd. Dus tantièmes enz. na het overdrachtstijdstip uitgekeerd, worden wel getroffen door Loonbelasting en Inkomstenbelasting 1941. Als concessie geldt daarbij, dat deze belooningen, voor zoover zij geen vereffenaarsloon zijn, kunnen worden belast op den voet van artikel 48, Inkomstenbelasting 1941. De tantièmes, vóór het overdrachtstijdstip uitgekeerd, zijn natuurlijk altijd belastbaar.

Uitdrukkelijk wordt verder bepaald, dat het overdrachtstiidstip niet kan vallen vóor den datum van het besluit tot ontbinding. Vanuit de fictie van de maatschap van aandeelhouders op het overdrachtstijdstip worden dan bij verkoop aan derden of aan enkele aandeelhouders, de te heffen belasting op speculatiewinsten en waardevermeerdering bij over gang van onroerend goed enz. berekend. (Eerste Uitvoeringsbeschikking art. $3 e$ leden 2 en 3 ).

Ten aanzien van de waardevermeerderingsbelasting geldt hetzelfde als ten opzichte van het normale geval is vermeld. (Art. 3, lid 3 Eerste Uitv. besch.), tenzij men overdraagt vóór het overdrachtstijdstip. In dit geval beslissen de voorschriften, die van toepassing zijn zonder het Liquidatiebesluit.

Door een aanvullende bepaling wordt een dubbele heffing bij overdracht van aandeelen van vaste goederenmaatschappijen voorkomen.

Ten aanzien van de belasting op speculatiewinsten geldt voor de maatschap van aandeelhouders als de prijs, die van de waarde op de overdrachtsbalans en het tijdstip van overdracht als het tijdstip van verkrijging (art. 3, lid 2 Uitv. besch.).

Vrijstelling van omzetbelasting en registratierecht krijgt alleen diegene, die aandeelhouder op het overdrachtstijdstip is. Ook het feit, dat hij meer krijgt, dan met zijn aandeelenbezit in overeenstemming is, heeft geen invloed op deze vrijstellingen.

Bepaalt men het overdrachtstijdstip ingeval van artikel 6 vóór den datum van ontbinding, dan mist men de voordeelen van het Liquidatiebesluit. Dit kan weer aanleiding geven tot moeilijkheden, want het kan fiscaal van belang zijn, dat het overdrachtstijdstip gekozen wordt op een datum, voorafgaande aan het ontbindingsbesluit. Een oplossing zou dan kunnen zijn om alles over te dragen aan de firma van aandeelhouders en op een later tijdstip de firma definitief te reorganiseeren.

Hiermede is het geval, waarop artikel 6 betrekking heeft, in hoofdlijnen toegelicht.

Het is nu mogelijk, dat het bestaan van verschillende soorten aandeelen moeilijkheden geeft in verband met den regel, dat de aandeelhouders moeten deelnemen in verhouding tot hun aandeelenbezit. Het besluit kent eigenlijk alleen het geval, dat er maar één soort aandeelen is. De 
Leidraad licht dit nader toe en bepaalt, dat men bij meerdere soorten van aandeelen, de diverse soorten op verschillende bedragen moet waardeeren. Of de aandeelen een gelijke nominale waarde hebben, doet er verder niet toe.

Tot slot nog de volgende opmerkingen:

Of men nu in een bepaald geval tot liquidatie moet overgaan of niet, hangt van de bijzonderheden van het geval af. Ondanks alle voordeelen zal men bij vennootschappen met belangrijke overgangsreserves moeten beginnen met een belangrijk bedrag aan winstbelasting te betalen, een bedrag, dat in het geval, dat de overgangsreserves het bedrijf voor een groot gedeelte financieren, niet altijd gemakkelijk zal zijn vrij te maken. Vooral bij sterk ontwikkelde familievennootschappen zal dit een groot bezwaar zijn.

Daarnaast dan nog de moeilijkheden van het samenstellen van een firma-contract, moeilijkheden, die in heel veel gevallen de lust tot liquidatie zullen bekoelen. In elk geval zal het raadzaam zijn, alvorens het besluit tot ontbinding te nemen, de firmaovereenkomst definitief tot stand te brengen, zoodat men later niet voor verrassingen zal komen te staan.

\title{
KOSTENVERLOOP EN DIFFERENTIEELE CALCULATIE
}

\author{
door Dr. S. Kleerekoper
}

Het kan van algemeene bekendheid worden geaeht, dat de differentieele calculatie als regel wordt gemotiveerd met een beroep op een degressief totaal kostenverloop, hetwelk dan weer wordt verklaard met het optreden van constante kosten.

Wij willen in onderstaande analyse iets nader op deze materie ingaan ten einde te onderzoeken of hier wellicht misverstanden aanwezig zijn, die opheldering behoeven.

Wanneer de totale kostprijs van een hoeveelheid product van $\mathrm{P}$ producteenheden wordt voorgesteld door II geldeenheden en wanneer de toegevoegde kosten van een hoeveelheid van $\triangle P$ producteenheden worden voorgesteld door $\Delta l l$ geldeenheden dan wordt de breuk $\frac{\Delta \Pi}{\Delta \mathrm{P}}$ de differentieele kosten bij een productie $\mathrm{P}$ genoemd. Men merke op, dat deze differentieele kosten zelf weer een gemiddelden kostprijs voorstellen en wel den gemiddelden kostprijs van een zekere kleine hoeveelheid product van $\triangle \mathrm{P}$ eenheden als er reeds eerder $\mathrm{P}$ eenheden geproduceerd $z$ ijn. Men is natuurlijk ook vrij om $\triangle \mathrm{P}$ groot te nemen: zoowel de economische als de wiskundige analyse echter hebben hun grootste beteekenis als men $\triangle \mathrm{P}$ ten opzichte van $\mathrm{P}$ als een kleine grootheid aanneemt.

De integrale calculatie zou den kostprijs van de toegevoegde $\triangle \mathrm{P}$ eenheden berekenen met behulp van de breuk $\frac{\Pi+\Delta \Pi}{\mathrm{P}+\triangle \mathrm{P}}$. Differenticele en integrale kostprijzen zijn dus beide gemiddelden. Het verschil tusschen de differentieele en integrale calculatie is, dat de eerste den gemiddelden kostprijs van een zekere, aan een oorspronkeliike productie toegevoegde, hoeveelheid product geeft en de laatste den gemiddelden kostprijs van de geheele productie. 